\title{
Doctors and Nurses Grieve Too
}

\section{Kimberly Richardson*}

Widows of Opportunity, USA

For the last 7 months, my mother was in the hospital. I had the opportunity to see the interactions of my mother's doctors and nurses. They all grew to love and respect her personality and resiliency. On October 24, 2018, my mother coded twice and some of her doctors and nurses were there. I could see in their body languages that they were concerned and overwhelmed. We all were relieved when she recovered. Unfortunately, that night when she coded again she never recovered. I was by her side when she took her last breath. I walked out of the room and allowed the doctors and nurses to do their job. Her doctor came to me and said that they were doing everything to bring her back. Five minutes later her doctor came back and told me that she didn't make it. I looked up at him and he had tears in his eyes. When I walked in the nurses were standing around my mother's body and some of them were devastated. They left me to be alone. I stayed with my mom for an hour and then I left. When I walked out I noticed the nurses working. I can't imagine what the doctors and nurses go through after losing a patient, especially one that they grew to love/like. They all work long hours. When do they have time to grieve? This has been a trying year for my family and me and an even more trying year for the nurses and doctors that grew to love my mom.

Physicians and nurses are taught empathy, compassion and to distance themselves and create protective boundaries in medical and nursing. It's not professional for them to show emotions or feelings regarding the loss of a patient. There's a stigma when it comes to grieving. Crying was frequent in hospitals; $57 \%$ of doctors, $76 \%$ of nurses and $31 \%$ of medical students had cried at work in the hospital at least once and women cried significantly more often than men. Being a nurse significantly increased, whereas being a medical student significantly decreased, the likelihood of crying. Medical students reported the highest percentage of negative social consequences of their own crying (e.g., being ridiculed or screamed at). The main reason for all respondents' crying was identification and bonding with suffering and dying patients or their families. The respondents generally viewed crying by patients as a healthy response and they were empathetic towards the crying patient. About one-third of the respondents were interested in (or would consider) using psychological help to explore their own emotional reactions to crying [1].

It's unfair to expect a physician or nurse to shut their feelings off and not grieve. Some have established close bonds and relationships with their patients. It would be normal for them to grieve the loss of their loved ones but unprofessional for them to grieve the loss of their patients, especially ones that they grew a bond with. That's unrealistic and unfair. Grief unaddressed can cause depression, mood swings, alcohol or drug abuse, reckless behavior, weaken one's immune system, forgetfulness, detachment, bitterness and lack of trust and suicidal thoughts/attempts. According to the American Foundation for Suicide Prevention, An estimated 300-400 physicians die by suicide in the US per year [2-4].

It should be mandatory that doctors and nurses attend grief seminar as well as take time off to rejuvenate and clear their mind. I'm not recommending that for every loss that they encounter. I am definitely recommending that for those losses that have affected them more.

\section{Helpful Grieving Tips}

- Get help - Don't be a shame to seek help. It's okay to join a support group or go to a grief therapist. This gives them an opportunity to express their feelings confidentially without being judged.

- Be kind to yourself - Do something nice for yourself. Go get a massage, go to the spa, go to the movies, hang out with some positive people, rent a boat and relax on the lake or beach. Try a new haircut or style or color.

- Take care of yourself - Get rest on those days that you are off. Exercise helps mentally and physically.

- Take up an intense activity to relieve the stress.

- Eat and drink healthy - Don't fall victim to stress eating or abusing alcohol. Those are temporary fixes that can lead to permanent problems.

- Have fun - Do something fun that will take your mind off of your grief and make you feel better.

- Honor your patient's memory - You can write them a letter and dispose of it when you finish or keep it. If you established a close bond with them reach out to their family and find out if and when they are having a ceremony. Some families have memorial ceremonies on their loved ones death anniversary. You can donate to their favorite charity. You can visit their grave.

- Give back - Volunteer your time to their favorite charity. Donate to their favorite charity. Offer to help their family.

\section{References}

1. Wagner RE, Hexel M, Bauer WW, Kropiunigg U (1997) Crying in hospitals: A survey of doctors', nurses' and medical students' experience and attitudes. Med J Aust 166: 13-16.

2. Shanafelt TD, Boone S, Tan L, Dyrbye LN, Sotile W, et al. (2012) Burnout and satisfaction with work-life balance among US physicians relative to the genera US population. Arch Intern Med 172: 1377-1385

3. Shanafelt TD, Balch CM, Bechamps G, Russell T, Dyrbye L, et al. (2010) Burnout and medical errors among American surgeons. Ann Surg 251: 9951000.

4. Balch CM, Oreskovich MR, Dyrbye LN, Colaiano JM, Satele DV, et al. (2011) Personal consequences of malpractice lawsuits on American surgeons. J Am Coll Surg 213: 657-667.

*Corresponding author: Kimberly Richardson, President, Widows of Opportunity, USA, Tel: (803)-238-5301; E-mail: widowsofopportunity@yahoo.com

Received: October 01, 2018; Accepted: December 04, 2018; Published: December 11, 2018

Citation: Richardson K (2018) Doctors and Nurses Grieve Too. Prim Health Care 8: 317. doi: 10.4172/2167-1079.1000317

Copyright: (๑) 2018 Richardson K. This is an open-access article distributed under the terms of the Creative Commons Attribution License, which permits unrestricted use, distribution, and reproduction in any medium, provided the original author and source are credited. 